\title{
ON MEDUSA-BUDDING IN THE ANTHOMEDUSA, PODOCORYNE MINIMA (TRINCI)
}

\section{$\operatorname{AUTHOR}(S)$ :}

Uchida, Tohru; Sugiura, Yasuo

\section{CITATION:}

Uchida, Tohru ...[et al]. ON MEDUSA-BUDDING IN THE ANTHOMEDUSA, PODOCORYNE MINIMA (TRINCI). PUBLICATIONS OF THE SETO MARINE BIOLOGICAL LABORATORY 1977 , 24(1-3): 53-57

\section{ISSUE DATE:}

\section{7-11-30}

URL:

http://hdl.handle.net/2433/175959

RIGHT: 


\title{
ON MEDUSA-BUDDING IN THE ANTHOMEDUSA, PODOCORYNE MINIMA (TRINGI)
}

\author{
TOHRU UCHIDA \\ Biological Laboratory, Imperial Household, Tokyo \\ and \\ YASUO SUGIURA \\ Laboratory of Biology, Dokkyo University, Soka-shi, Saitama-ken
}

With Text-figures 1-2

In 1928 Kramp described a new hydromedusa from Japan under the name of Podocoryne simplex and later Uchida (1930, 1938, 1947 and 1964) recorded the same medusa from several localities of the Pacific. While studying a lot of specimens of this medusa, however, the writers came to the conclusion that Podocoryne simplex is nothing but a synonym of Podocoryne minima (Trinci, 1903) as was pointed out already by Russell (1954).

Podocoryne minima is widely distributed along the coasts of Japan but the materials here dealt with were mostly collected at Misaki, Kanagawa Prefecture from 1971 to 1976. In addition, some specimens from Amakusa, Kumamoto Prefecture were also examined. As little has been reported on medusa-budding in this species, the details of the observation made by the writers will be given in the present paper.

\section{Morphological Features of Medusa}

The medusa is very small, the height and width of the umbrella are almost equal and 0.3 to $0.9 \mathrm{~mm}$. The umbrella is globular, but somewhat narrowed and elevated in the upper part. The jelly is rather soft and thin. The four radial canals are distinct and straight, while the ring canal is narrow and indistinct. The marginal tentacles are each prolonged from the oval tentacle bulb and fundamentally four in number, though tending to decrease their number and length. Frequently some of them are missing or ill-developed. They are liable to contract but sometimes are extended over several times the diameter of the umbrella. When fully extended, nematocyst clusters can be obviously seen as transverse stripes on the tentacle shaft but its basal part. The velum is well-developed and squarish, because the ring canal runs straight between the perradial tentacle bulbs. When the velum is spread extensively, only a small aperture is left at the center under the umbrella. The manubrium bearing medusa-buds and terminating in four oral tentacles, each without further branching and ending in a spiny cluster of nematocysts, is extensile

Publ. Seto Mar. Biol. Lab., XXIV (1/3), 53-57, 1977.

(Article 8) 
under the peduncle, transparent and hanging down from the ceiling of the subumbrellar cavity just like a funnel. It reaches two-third or more down of the height of the subumbrellar cavity but never beyond the level of the velum. The manubrium and the upper part of tentacle bulbs are brownish in colour. No significant differences in size and shape are found between sexually mature and immature medusae. Medusa-buds will be described later.

\section{Medusa just liberated}

Usually liberated young medusae rapidly enlarge in an hour, though sometimes medusa-buds may be bulged on the mother medusa. The medusae just liberated are somewhat depressed and generally 0.25 to $0.35 \mathrm{~mm}$ in height and 0.35 to 0.40 $\mathrm{mm}$ in width, but bulged medusae just mentioned may reach $0.45 \mathrm{~mm}$ in height and width. The outer surface of the umbrella is sprinkled with conspicuous round nematocysts which are protruded from and distributed almost evenly over the surface though slightly denser in the lower than in the upper half. The shape and size of expanded medusae just liberated are almost the same as in all the young medusae so far observed. The tentacle is very variable in length and number in the present species and there are found some medusa-buds which are furnished already with four long tentacles before liberation. Generally one to four medusa-buds are found in newly liberated medusae (Fig. 1, A, B).

\section{Medusa-Bud Formation}

In this species, medusa-buds can be observed almost in every medusa captured throughout all the seasons. The buds are each protruded at first as a minute transparent and structureless medusa nucleus and then grow to hemispherical globes, superficially without any definite structure. In many cases, daughter medusa-buds are already formed on the medusa-buds fully developed but not yet liberated. In the formation of medusa-buds, the primary pair of medusa-nuclei (No. 1 and No. 2) appear on the upper part of the manubrium at respective ends of an interradius, then the second pair (No. 3 and No. 4) in the other interradius but at somewhat lower level. The medusa-bud No. 1 usually remains much larger than the No. 2 before the following No. 3 and No. 4 buds grow up (Fig. 1, G). It seems that there is no rule concerning the position of the No. 3 bud as to the line running between the No. 1 and No. 2 buds. Further successive buds appear below the four buds described above (Fig. 1, D, E). The second cycle of buds from No. 5 to No. 8 will follow the first cycle consisting of No. 1 to No. 4 buds and further No. 9 medusa-buds belonging to the third cycle has ever been found, though only once, by the writers.

\section{Gonad Formation}

To the gonad of Podocoryne minima, Russell (1954) has briefly referred as follows: 


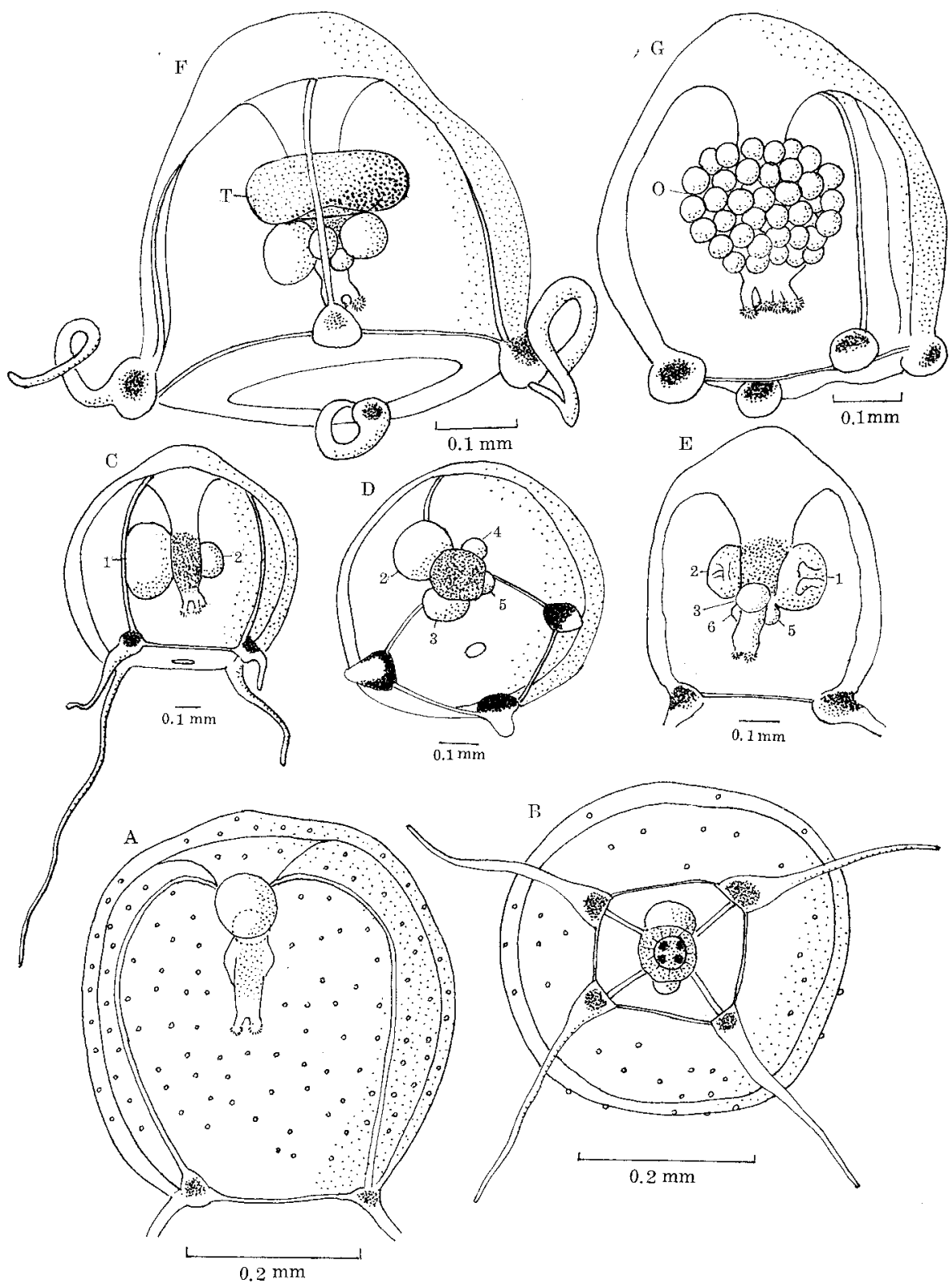

Fig. 1. Podocoryne minima (Trinci), medusae in various stages.

A) A medusa just liberated (side view).

B) A medusa just liberated (oral view).

C) A young medusa with two medusa-buds of different sizes in an interradius (side view).

D) A young medusa with four medusa-buds after the release of No. 1 bud (dorsal view).

E) A young medusa bearing the cluster of six medusa-buds with No. 5 and No. 6 buds at a lower level (side view).

F) An adult male medusa (side view). T: Testes

G) An adult female medusa (side view). O: Ovaries 
"Medusa-buds and gonads may occur simultaneously. The gonads are interradial, but it appears from a drawing made by Mr. Browne that when fully developed they may completely surround the stomach as in Rathkea and Lizzia." Though he did not give any comments on the sex of the medusa, in all probabilities Russell's mature medusa seemingly belonged to the male, because no ova are represented in this figure. According to the present observations, the testes are discoidal and surrounding the upper part of the manubrium exactly as in his figure (Fig. 1, F and Fig. 2, $\mathrm{H})$. This time, however, female medusae having ovaries were discovered. They are clearly distinguished from the male by having well-developed ova (Fig. 1, G and Fig. 2, I). As far as the present observations are concerned, ovaries appear first at the junction between the peduncle and manubrium. In early stages, only

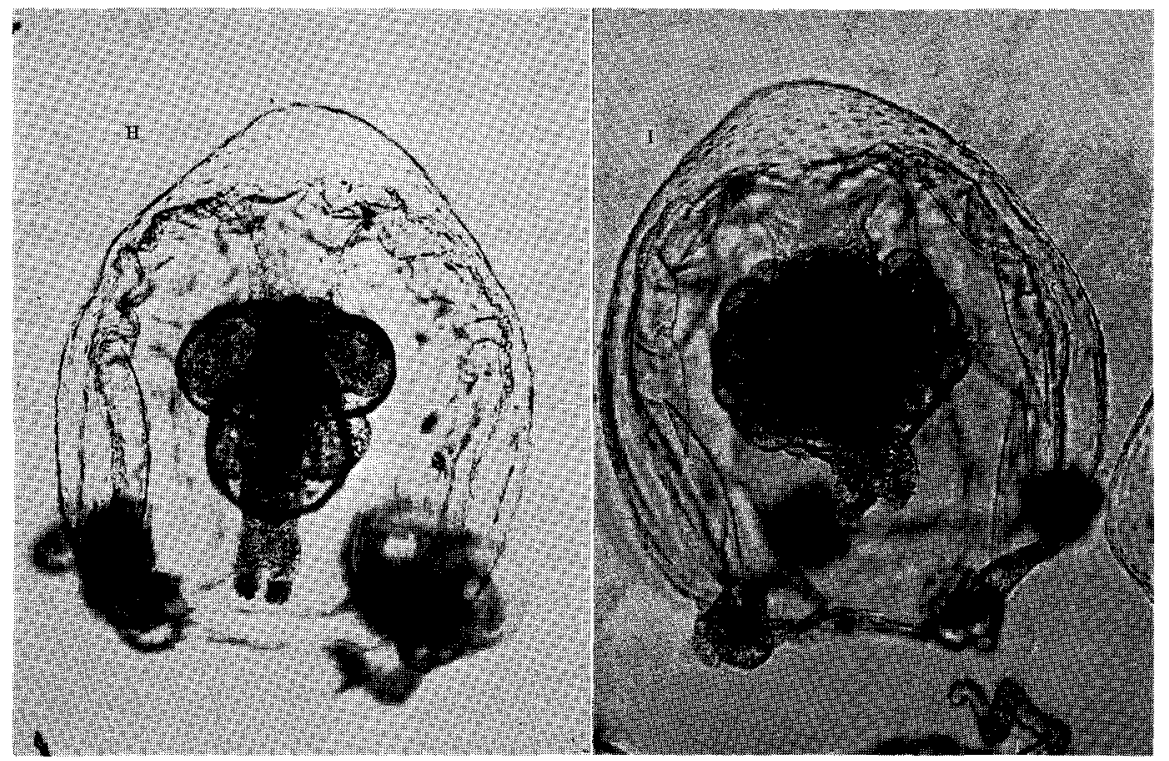

Fig. 2. Podocoryne minima (Trinci), sexually mature medusac.

H) An adult male medusa (side view). ca. $100 \times$

I) An adult female medusa (side view). ca. $100 \times$

the uppermost part of the manubrium is encircled with ova arranged in a single layer, but in the fully ripe female medusa the manubrium is entirely enclosed in the barrel-shaped cluster of a number of eggs. Generally, at least in the earlier stages of gonad formation, young gonads exist together with medusa-buds, but with the gonadal growth medusa-buds are generally replaced by gonads and finally only the latter are found there. Sexually mature medusae have been captured only rarely in contrast with common and abundant occurrences of medusae with medusabuds, only two males and two females are found in the present collection containing several hundred medusae. The two males, both captured on July 16, 1972, are $0.5 \mathrm{~mm}$ in height and $0.5 \mathrm{~mm}$ in width, and $0.4 \mathrm{~mm}$ in height and $0.5 \mathrm{~mm}$ in width respectively, while the two females were captured on August 1, 1971 and July 27, 
1975 and equally $0.6 \mathrm{~mm}$ in height and $0.5 \mathrm{~mm}$ in width. Both the gonads and medusa-buds are observed in the same individuals except in one fully developed female and in all the sexually mature medusae developing gonads are located above the cluster of medusa-buds. The testes are $0.23 \mathrm{~mm}$ in diameter and $0.12 \mathrm{~mm}$ in thickness in the $0.5 \mathrm{~mm}$ high male and $0.23 \mathrm{~mm}$ in diameter and $0.10 \mathrm{~mm}$ in thickness in the other $0.4 \mathrm{~mm}$ in height, while the ovaries are $0.20 \mathrm{~mm}$ in diameter and $0.05 \mathrm{~mm}$ in thickness in a developing stage and $0.23 \mathrm{~mm}$ in diameter and $0.26 \mathrm{~mm}$ in thickness in the fully grown state. There are no significant differences in size and general structures between the medusae with gonads and those without them.

\section{Seasonal Appearance}

The present materials were gathered from the plankton samples collected at the entrance to Aburatsubo Bay in Misaki once a week in the past five years. No medusae were found in the winter season from November to January. Whereas, numerous medusae were obtained in spring and summer, but it is noteworthy that the medusae were extremely decreased, so far as the writers were aware, in June every year.

\section{Acknowledgement}

The writers are greatly indebted to the director and the staff of the Misaki Marine Biological Station for their facilities.

\section{REFERENGES}

Kramp, P.L. 1928. Papers from Dr. Th. Mortensen's Pacific Expedition 1914-16. XLIII. Hydromedusae, I. Anthomedusae. Vidensk. Medd. naturh. 85, 45.

-1961. Synopsis of the Medusae of the world. Jour. Mar. Biol. Ass. U.K. 40, 66-71.

1968. The Hydromedusae of the Pacific and Indian Oceans. Sect. II and III. Dana Rep. Nos. 72, 28-29.

Mayer, A.G. 1910. Medusae of the world. I. Hydromedusae. 135-142.

Russell, F.S. 1954. The medusae of the British Isles. 120-136.

Uchida, T. 1930. Beitrage zur Kenntnis der Japanischen Hydromedusen. Zool. Anz. 88, (11/12), 331 .

1938. Medusae in the Vicinity of the Amakusa Marine Biological Station. Bull. Biogeogr. Soc. Japan. 8, (10), 145.

1947. Some Medusae from the Central Pacific. Jour. Fac. Sci. Hokkaido Imp. Univ. VI. Zool. 9, (3), 301.

1964. A New Hydroid Species of Cytaeis, with some remarks on the Interrelationship in the Filifera. Publ. Seto. Mar. Biol. Lab. 12, (2), 138. 